\title{
Cinnamon Polyphenol Extract Inhibits Hyperlipidemia and Inflammation by Modulation of Transcription Factors in High-Fat Diet-Fed Rats
}

\author{
Zeynep Tuzcu,, Cemal Orhan, ${ }^{2}$ Nurhan Sahin, ${ }^{2}$ Vijaya Juturu, ${ }^{3}$ and Kazim Sahin ${ }^{2}$ \\ ${ }^{1}$ Division of Biology, Faculty of Science, Firat University, Elazig, Turkey \\ ${ }^{2}$ Department of Animal Nutrition, Faculty of Veterinary Science, Firat University, Elazig, Turkey \\ ${ }^{3}$ Research and Development, OmniActive Health Technologies Inc., Morristown, NJ, USA \\ Correspondence should be addressed to Kazim Sahin; nsahinkm@yahoo.com
}

Received 13 January 2017; Accepted 26 February 2017; Published 15 March 2017

Academic Editor: Jasminka Giacometti

Copyright ( 2017 Zeynep Tuzcu et al. This is an open access article distributed under the Creative Commons Attribution License, which permits unrestricted use, distribution, and reproduction in any medium, provided the original work is properly cited.

\begin{abstract}
We evaluated the effects of cinnamon polyphenol extract on hepatic transcription factors expressions including SREBP-1c and LXR- $\alpha$ in rats fed high fat diet (HFD). Twenty-eight Wistar rats were allocated into four groups: (i) normal control: animals fed with normal chow; (ii) cinnamon: animals supplemented with cinnamon polyphenol; (iii) HFD: animals fed a high-fat diet; and (iv) HFD + cinnamon: animals fed a high-fat diet and treated with cinnamon polyphenol. Obesity was linked to hyperglycemia, hyperlipidemia, and oxidative stress as imitated by elevated serum glucose, lipid profile, and serum and liver malondialdehyde (MDA) concentrations. Cinnamon polyphenol decreased body weight, visceral fat, liver weight and serum glucose and insulin concentrations, liver antioxidant enzymes, and lipid profile $(P<0.05)$ and reduced serum and liver MDA concentration compared to HFD rats $(P<0.05)$. Cinnamon polyphenol also suppressed the hepatic SREBP-1c, LXR- $\alpha$, ACLY, FAS, and NF- $\kappa$ B p65 expressions and enhanced the PPAR- $\alpha$, IRS-1, Nrf2, and HO-1 expressions in the HFD rat livers $(P<0.05)$. In conclusion, cinnamon polyphenol reduces the hyperlipidemia, inflammation, and oxidative stress through activating transcription factors and antioxidative defense signaling pathway in HFD rat liver.
\end{abstract}

\section{Introduction}

Obesity is an important health problem that characterized excessive fat accumulation in the body resulting from an imbalance in energy intake and expenditure [1]. It is known to be a risk factor for numerous metabolic complaints such as diabetes, atherosclerosis, hyperlipidemia, and cancer $[2,3]$. Consumption of high-fat diet causes a leading obesity and obesity-related complications including hyperlipidemia and oxidative stress $[4,5]$. Liver fat synthesis is an extremely modified metabolic pathway which is vital for actual lowdensity lipoprotein production and is, therefore, important for energy delivery to other tissues [6]. Transcription factors such as the sterol regulatory element-binding protein 1 (SREBP-1) and liver X receptors (LXRs) and several enzymes including ATP-citrate lyase (ACL), acetyl-CoA carboxylase (ACC), and fatty acid synthase (FAS) have vital roles in this process [7-9]. SREBP-1 may control the ectopic accumulation of fat and may set the target gene FAS, an important enzyme that controls the amount of fatty acid synthesis $[10,11]$. Obesity-induced insulin resistance triggers inflammation in the liver through the accumulation of reactive oxygen species that trigger nuclear factor kappa beta (NF- $\kappa \mathrm{B})$ pathway [12]. Besides systemic and hepatic fat metabolism deterioration, inflammation is a major factor underlying liver damage in diabetes $[13,14]$. The peroxisome proliferator-activated receptor $\alpha(\operatorname{PPAR} \alpha)$, which is extremely expressed in the liver, shows a vital role in the modulation of liver lipid metabolism [15].

Some potent drugs carry the risk of side effects on the central nervous system and the cardiovascular system in the treatment of obesity $[16,17]$. Natural products can show an obvious role in the prevention of obesity and associated metabolic diseases. Cinnamon has been used as 
spice for a long time [18]. In addition it is gained from the inner bark of tropical evergreen cinnamon plants [18]. There are two main types of cinnamon: True or Ceylon cinnamon (Cinnamomum verum and C. zeylanicum) and cassia cinnamon (C. aromaticum and C. burmannii). That cinnamon as a dietary supplement has antioxidant, antiinflammation, and presently discovered antihyperlipidemia and antiobesity effect properties [19, 20]. Experimental and clinical studies have shown that cinnamon could be attributed to its beneficial effects on hyperlipidemia and glucose utilization [21, 22]. A study reported that cinnamon increases insulin sensitivity and liver glycogen by modulating insulin signaling and glycogen synthesis in insulin-resistant rats [22]. Research in animal models has also proven that cinnamon effectively prevents obesity caused by high-fat diets [23]. However, the underlying exact mechanisms are still unclear. Hence, in this study, the effects of cinnamon polyphenol extract on PPAR $\alpha$-mediated target genes involved in glucose and lipid metabolism, including SREBP-1c, LXRs, ATP-citrate lyase (ACLY), and FAS, and expression of molecular targets of inflammation (NF- $\kappa$ B) and antioxidant status (Nrf2 pathway) in the liver were examined to investigate more detailed mechanisms in the improvement of fatty liver with high-fat diet.

\section{Materials and Methods}

2.1. Animals. Twenty-eight Wistar rats (weighing $180 \pm 20 \mathrm{~g}$ ) were kept under a $12 \mathrm{~h}$ light/dark cycle at $22 \pm 2^{\circ} \mathrm{C}$, with feed and water ad libitum. Rats had free access to diet and water. Rats received humanitarian care according to standards defined in the "Guidelines for the Care and Use of Laboratory Animals" delivered by the National Academy of Sciences and published by the National Institutes of Health and permitted by the Ethical Commission of the Firat University, Elazig, Turkey. The composition of diets (control and HFD) is shown in Table 1. For obesity induction, animals were fed with HFD for 12 weeks and compared with rats fed normal diet.

2.2. Experimental Diets and Design. After acclimatization for 2 weeks, 28 rats were randomly allocated into four groups, with 7 rats in each group: (i) normal control group: animals fed with normal chow ( $12 \%$ of calories as fat) throughout the experimental period of 12 weeks; (ii) cinnamon group: rats fed with normal chow and administered with cinnamon polyphenol (100 mg/kg b.wt.) throughout the experimental period of 12 weeks; (iii) HFD group: rats fed with high-fat diet [ $42 \%$ of calories as fat] throughout the experimental period of 12 weeks; and (iv) HFD + cinnamon group: rats fed a high-fat diet and administered with cinnamon polyphenol throughout the experimental period of 12 weeks. Rats were orally treated with cinnamon polyphenol extract $[100 \mathrm{mg} / \mathrm{kg}$ b.wt. dissolved in $5 \%$ dimethyl sulfoxide (DMSO)] daily by oral gavage in olive oil $(1 \mathrm{ml} / \mathrm{kg}$ b.wt./day) to the end of the experiment. The amount of cinnamon polyphenol extract used was based upon an earlier study presenting a positive result of $100 \mathrm{mg}$ of cinnamon per kilogram on diabetic rats [24]. The control rats in this study received similar amounts of sunflower oil by gavage. Cinnamon product (Product Code: 33002; Lot Number: CINP10001b) obtained from Cinnamomum zeylanicum by the aqueous-alcoholic extraction used in this study was provided by OmniActive Health Technologies Ltd. (Pune, India). The test compound contains $18.41 \%$ total polyphenols and it is light to dark reddish brown free flowing powder with an astringent taste. The quality of cinnamon polyphenol extract was confirmed to comply with strict quality control measures and found free of endotoxin and heavy metals.

At the end of the study, the blood was collected by cardiac puncture after an overnight fast and all rats were sacrificed by cervical dislocation. The visceral fat and liver samples were removed and weighed after sacrificing the animals.

2.3. Biochemical Estimations. Serum was prepared by centrifuging the blood at $3,000 \times \mathrm{g}$ for 10 minutes and used for biochemical parameters and malondialdehyde (MDA) analyses. Sera samples were prepared by centrifuging the blood at $3,000 \times \mathrm{g}$ for $10 \mathrm{~min}$ and used for the analyses of biochemical parameters and MDA. Serum parameters were determined using an automated analyzer (Samsung LABGEOPT10, Samsung Electronics Co., Suwon, Korea). Repeatability and device/method exactness of LABGEOPT10 were documented according to the IVR-PT06 guideline. The concentration of serum insulin was measured with the Rat Insulin kits (Linco Research Inc., St. Charles, MO, USA) by ELISA (Elx-800, Bio-Tek Instruments Inc., Vermont, USA). The sensitivity of the assays for insulin was $0.36 \mathrm{ng} / \mathrm{ml}$. The interassay and intra-assay coefficients of variation were $5.3 \%$ and $7.5 \%$ for insulin. Liver MDA levels were determined according to the method described by Karatepe [25] by HPLC with a Shimadzu UV-Vis SPD-10 AVP detector, a CTO-10 AS VP column, and a mobile phase comprised of $30 \mathrm{mM} \mathrm{KH}_{2} \mathrm{PO}_{4}$ and methanol $(82.5: 17.5, \mathrm{v} / \mathrm{v}, \mathrm{pH} 3.6)$ at a flow rate of $1.2 \mathrm{ml} / \mathrm{min}$. Column effluents were monitored at $250 \mathrm{~nm}$. Liver homogenate $(10 \%, \mathrm{w} / \mathrm{v})$ was prepared in $10 \mathrm{mM}$ phosphate buffer $(\mathrm{pH} 7.4)$ and centrifuged at $13,000 \times \mathrm{g}$ for 10 minutes at $4^{\circ} \mathrm{C}$. The resulting supernatant was collected and kept at $-80^{\circ} \mathrm{C}$ for MDA estimation.

Total antioxidant capacity (TAC) was determined by dark blue-green color reduction 2,2' -azino-bis 3ethylbenzothiazoline-6-sulfonate (ABTS) by antioxidants to its colorless form via the antioxidants in the sample [26]. In this analysis, ABTS is incubated with potassium persulfate to produce ABTS oxidation. Briefly, $10 \mathrm{mg}$ of ABTS was dissolved in $10 \mathrm{~mL}$ of an aqueous solution containing $2.5 \mathrm{mmol} / \mathrm{L}$ potassium persulfate and allowing the mixture to stand in the dark at room temperature for one to four hours before use. For the study of samples, ABTS oxidized stock solution was diluted with deionized water to an absorbance of 0.70 at $734 \mathrm{~nm}$. After addition of $1 \mathrm{~mL}$ diluted ABTS with $10 \mu \mathrm{L}$ of serum oxidized, the absorbance readout was taken ten minutes after the first mixing. The results were expressed in $\mathrm{mmol}$ Trolox E/L.

Activity of total superoxide dismutase (SOD) in the homogenized liver tissue (in $20 \mathrm{mM}$ HEPES (N-2 hydroxyethyl piperazine- $\mathrm{N}^{\prime}$-2-ethanesulfonic acid) buffer, $1 \mathrm{mM}$ 
TABLE 1: Composition of diets ( $\mathrm{g} / \mathrm{kg}$ diet) fed to rats.

\begin{tabular}{lcc}
\hline & Control & HFD \\
\hline Casein & 200.0 & 200.0 \\
Starch & 579.5 & 150.0 \\
Sucrose & 50.0 & 149.5 \\
Soybean oil & 70.0 & - \\
Beef tallow & - & 400.0 \\
Cellulose & 50.0 & 50.0 \\
Vitamin-mineral premix ${ }^{*}$ & 45.0 & 45.0 \\
L-Cysteine & 3.0 & 3.0 \\
Choline bitartrate & 2.5 & 2.5 \\
\hline
\end{tabular}

${ }^{*}$ The vitamin-mineral premix provides the following (per $\mathrm{kg}$ ): all-transretinyl acetate, $1.8 \mathrm{mg}$; cholecalciferol, $0.025 \mathrm{mg}$; all-rac-a-tocopherol acetate, $12.5 \mathrm{mg}$; menadione (menadione sodium bisulfate), $1.1 \mathrm{mg}$; riboflavin, $4.4 \mathrm{mg}$; thiamine (thiamine mononitrate), $1.1 \mathrm{mg}$; vitamin B-6, $2.2 \mathrm{mg}$; niacin, $35 \mathrm{mg}$; Ca-pantothenate, $10 \mathrm{mg}$; vitamin B-12, $0.02 \mathrm{mg}$; folic acid, $0.55 \mathrm{mg}$; $d$-biotin, $0.1 \mathrm{mg}$; manganese (from manganese oxide), $40 \mathrm{mg}$; iron (from iron sulfate), $12.5 \mathrm{mg}$; zinc (from zinc oxide), $25 \mathrm{mg}$; copper (from copper sulfate), $3.5 \mathrm{mg}$; iodine (from potassium iodide), $0.3 \mathrm{mg}$; selenium (from sodium selenite), $0.15 \mathrm{mg}$; choline chloride, $175 \mathrm{mg}$.

ethylene glycol tetraacetic acid, $210 \mathrm{mM}$ mannitol, and $70 \mathrm{mM}$ sucrose, $\mathrm{pH} 7.2$, per $\mathrm{g}$ of tissue) was determined by a commercial kit (Cayman Chemical, Ann Arbor, MI, USA) according to the manufacturer's instructions. The supernatant was collected after centrifugation at $12.000 \mathrm{~g}$ for $20 \mathrm{~min}$ at $4^{\circ} \mathrm{C}$. The supernatant was purified from the salt by passing through a Sephadex G-25 column. The samples were also treated with a mixture of ethanol-chloroform $(2: 1$, $\mathrm{v} / \mathrm{v}$ ) and distilled water to remove hemoglobin and red blood cells and the absorbance plate was read on a reader (BioTek Instruments, Inc., Vermont, USA) at $450 \mathrm{~nm}$. The results were expressed as units per mg protein (U/mg protein) using standard calibration curve. Catalase (CAT) activity was also determined in homogenized tissue $(50 \mathrm{mM}$ potassium phosphate, $1 \mathrm{mM}$ EDTA, $\mathrm{pH} 7$, in cold buffer, per tissue) using a commercial kit (Cayman Chemical, Ann Arbor, MI, USA) according to the manufacturer's instructions. The supernatant was collected after centrifugation at $12,000 \mathrm{~g}$ for 20 minutes at $4^{\circ} \mathrm{C}$. A formaldehyde solution was used as standard. The absorbance of standard and samples was taken at $540 \mathrm{~nm}$ using a plate reader (Bio-Tek Instruments, Inc. Vermont, USA). Catalase activity was expressed as $\mathrm{nmol} / \mathrm{min} / \mathrm{mg}$ protein using standard calibration curve. The activity of glutathione peroxidase (GSHPx) was analyzed according to the manufacturer's instructions (Cayman Chemical, Ann Arbor, MI, USA). Liver tissue was homogenized with the Polytron Homogenizer in cold buffer $(50 \mathrm{mM}$ Tris- $\mathrm{HCl}, \mathrm{pH}$ 7.5, $5 \mathrm{mM}$ EDTA, and $1 \mathrm{mM}$ dithiothreitol) per tissue and then subjected to centrifugation at $10,000 \mathrm{~g}$ for 15 minutes at $4^{\circ} \mathrm{C}$. This method is based on the oxidation of NADPH to NADP ${ }^{+}$, which is accompanied by an absorbance drop at $340 \mathrm{~nm}$ and GSHPx activity was measured by initiating the reaction with $2.4 \mathrm{mM}$ cumene hydroperoxide. One unit is defined as the amount of enzyme that oxidizes $1 \mu \mathrm{mol}$ of NADPH per min at $25^{\circ} \mathrm{C}$. The absorbance was read every minute at $340 \mathrm{~nm}$ using a plate reader (Bio-Tek Instruments, Inc., Vermont, USA) to obtain at least 5 time points. The GSHPx activity was calculated in $\mathrm{nmol} / \mathrm{min} / \mathrm{mg}$ of protein using standard calibration curve.

2.4. Western Blot Analyses. Protein extraction was performed by standardizing the liver in $1 \mathrm{ml}$ of ice-cold hypotonic buffer (buffer A) containing 10 mM HEPES (2-(4-(2-hydroxyethyl)1-piperazinyl) ethane sulfonic acid, $\mathrm{PH} 7.8,10 \mathrm{mM} \mathrm{KCl}$, $2 \mathrm{mM} \mathrm{MgCl} 2,1 \mathrm{mM}$ dithiothreitol (DTT), $0.1 \mathrm{mM}$ EDTA, and $0.1 \mathrm{mM}$ phenylmethylsulfonyl fluoride (PMSF) for Western blot analysis. The homogenate was mixed with $80 \mu \mathrm{l}$ of $10 \%$ Nonidet P-40 (NP-40) solution and then centrifuged at $14,000 \times \mathrm{g}$ for 2 minutes. The precipitates were washed once with $500 \mu \mathrm{L}$ buffer A and $40 \mu \mathrm{L} 10 \%$ NP-40, centrifuged, and resuspended in a $200 \mu \mathrm{L}$ buffer containing $50 \mathrm{mM}$ HEPES, pH 7.8, $50 \mathrm{mM} \mathrm{KCl,} 300 \mathrm{mM} \mathrm{NaCl}, 0.1 \mathrm{mM}$ EDTA, $1 \mathrm{mM}$ DTT, 0.1 mM PMSF, and $20 \%$ glycerol) and recentrifuged at $14,800 \times \mathrm{g}$ for $5 \mathrm{~min}$. The concentration of the protein was determined according to the procedure described by Lowry using a protein assay kit (Sigma, St. Louis, MO, USA). The supernatant was collected and used for the determination of SREBP-1c, LXRs, ACLY, FAS, NF$\kappa \mathrm{B}$ p65, PPAR $\alpha$, p-IRS-1, Nrf-2, and HO-1 according to the previously described method [27]. Briefly, $50 \mu \mathrm{g}$ of proteins was electrophoresed and then transferred to a nitrocellulose membrane (Schleicher and Schuell Inc., Keene, NH, USA). The phosphorylated form of antibodies against SREBP-lc, LXRs, ACLY, FAS, NF- $\kappa$ B p65, PPAR $\alpha$, p-IRS-1, Nrf-2, and HO-1 (Abcam, Cambridge, UK) was diluted $(1: 1000)$ in the same buffer containing $0.05 \%$ Tween-20. Protein loading was controlled using monoclonal mouse antibody against $\beta$-actin (A5316; Sigma). The bands were examined densitometrically using ImageJ, an image analysis system (National Institute of Health, Bethesda, USA).

2.5. Statistical Analysis. Data were stated as mean \pm SE. The alteration among groups was analyzed using one-way analysis of variance (ANOVA) followed by the Tukey post hoc test (SAS Institute: SAS User's Guide: Statistics), and $P<0.05$ was considered statistically significant.

\section{Results}

3.1. Effect of Cinnamon Extract on Body Weight and Visceral Fat in HFD-Fed Rats. The effect of cinnamon polyphenol extract treatment on the final body weight, feed consumption, and visceral fat and liver mass was shown in Table 2. HFD feeding increased final body weight, visceral fat, and liver weight by $33.1 \%, 258.3 \%$, and $34.8 \%$ and decreased feed intake by $16.9 \%$ as compared to the control rats $(P<0.001)$. Although the cinnamon polyphenol extract treatment decreased body weight, visceral fat, and liver weight by $8.4 \%, 36.6 \%$, and $17.7 \%$ in the HFD-fed rats $(P<0.001)$, the HFD-fed rats treated with cinnamon still had a final body weight and visceral fat higher than those of the control rats $(P<0.05)$. No significant difference was found in the feed intake between HFD-fed rats and HFD-fed rats treated with cinnamon polyphenol extract $(P>0.05)$. 
TABLE 2: Effect of cinnamon polyphenol extract supplementation on the body weight, visceral fat, and the liver weight in rats fed with HFD for 12 weeks.

\begin{tabular}{|c|c|c|c|c|}
\hline \multirow{2}{*}{ Item } & \multicolumn{4}{|c|}{ Groups } \\
\hline & Control & Cinnamon & HFD & HFD + cinnamon \\
\hline Final BW (g) & $301.43 \pm 5.27^{\mathrm{C}}$ & $298.86 \pm 6.50^{\mathrm{C}}$ & $401.29 \pm 5.07^{\mathrm{A}}$ & $367.71 \pm 2.75^{\mathrm{B}}$ \\
\hline Feed intake $(\mathrm{g} / \mathrm{d})$ & $22.77 \pm 0.44^{\mathrm{A}}$ & $22.96 \pm 0.40^{\mathrm{A}}$ & $18.93 \pm 0.44^{\mathrm{B}}$ & $19.91 \pm 0.41^{\mathrm{B}}$ \\
\hline Visceral fat (g) & $6.62 \pm 0.45^{\mathrm{C}}$ & $6.35 \pm 0.33^{\mathrm{C}}$ & $23.72 \pm 1.58^{\mathrm{A}}$ & $15.04 \pm 0.48^{\mathrm{B}}$ \\
\hline Liver (g) & $11.63 \pm 0.25^{\mathrm{C}}$ & $11.79 \pm 0.42^{\mathrm{C}}$ & $15.68 \pm 0.38^{\mathrm{A}}$ & $12.90 \pm 0.38^{\mathrm{B}}$ \\
\hline
\end{tabular}

HFD, high-fat diet; data are expressed as mean \pm SEM of 7 rats from each group. A, B, and C: means in the same row with different superscripts are significant $(P<0.05)$.

TABLE 3: Effects of cinnamon polyphenol extract biochemical parameters levels in rats fed with HFD for 12 weeks.

\begin{tabular}{lcccc}
\hline Item & & & Groups & \\
& Control & Cinnamon & HFD & HFD + cinnamon \\
\hline Glucose (mg/dl) & $75.86 \pm 2.62^{\mathrm{C}}$ & $76.57 \pm 3.34^{\mathrm{C}}$ & $200.86 \pm 3.97^{\mathrm{A}}$ & $158.43 \pm 2.07^{\mathrm{B}}$ \\
Insulin (ng/mL) & $1.61 \pm 0.04^{\mathrm{C}}$ & $1.55 \pm 0.04^{\mathrm{C}}$ & $8.21 \pm 0.29^{\mathrm{A}}$ & $4.47 \pm 0.23^{\mathrm{B}}$ \\
FFA (mM) & $1.74 \pm 0.11^{\mathrm{C}}$ & $1.48 \pm 0.06^{\mathrm{C}}$ & $5.03 \pm 0.14^{\mathrm{A}}$ & $2.25 \pm 0.07^{\mathrm{B}}$ \\
T-C (mg/ml) & $66.51 \pm 5.58^{\mathrm{B}}$ & $53.26 \pm 1.90^{\mathrm{B}}$ & $91.71 \pm 2.28^{\mathrm{A}}$ & $61.43 \pm 1.81^{\mathrm{B}}$ \\
HDL-C (mg/dl) & $15.29 \pm 0.57^{\mathrm{BC}}$ & $13.57 \pm 0.77^{\mathrm{C}}$ & $22.57 \pm 0.53^{\mathrm{A}}$ & $18.57 \pm 0.43^{\mathrm{AB}}$ \\
TG (mg/dl) & $25.86 \pm 1.26^{\mathrm{C}}$ & $24.14 \pm 1.81^{\mathrm{C}}$ & $57.57 \pm 2.08^{\mathrm{A}}$ & $41.85 \pm 1.49^{\mathrm{B}}$ \\
AST (U/L) & $146.413 \pm 4.40$ & $142.71 \pm 4.30$ & $157.00 \pm 8.28$ & $154.22 \pm 5.38$ \\
ALT (U/L) & $83.65 \pm 6.59$ & $81.86 \pm 4.18$ & $89.14 \pm 4.39$ & $86.43 \pm 5.16$ \\
\hline
\end{tabular}

HFD, high-fat diet; FFA, free fatty acids; T-C, total cholesterol; HDL-C, high-density lipoprotein cholesterol; TG, triglycerides; AST, aspartate aminotransferase; ALT, alanine transferase. Data are expressed as mean \pm SEM of 7 rats from each group. A, B, and C: means in the same row with different superscripts are significant $(P<0.05)$.

\subsection{Effect of Cinnamon Extract on Biochemical Parameters} in HFD-Fed Rats. Table 3 shows the effect of cinnamon polyphenol extract on supplementation on carbohydrate and lipid profile in HFD-fed rats. As seen in the table, HFD feeding increased the serum levels of glucose and insulin, free fatty acid (FFA), total cholesterol, HDL-C, and LDL-C, as well as TG in HFD rats $(P<0.001)$. The hypertriglyceridemia and elevated lipid indicators in HFD-fed rats were reduced with cinnamon polyphenol extract supplementation. HFD did not cause a significant increase in aspartate transaminase (AST) and alanine transaminase (ALT) in the duration of the treatment, and the levels remained more or less unaffected in cinnamon polyphenol extract supplemented rats $(P>0.05)$.

\subsection{Effect of Cinnamon Extract on Antioxidant Status in HFD-} Fed Rats. Serum and liver MDA levels increased by $158.8 \%$ and $81.7 \%(P<0.001$; Table 4$)$ and serum TAC, liver SOD, CAT, and GSHPx decreased by $67.6,54.7,34.4 \%$, and $56.4 \%$ upon obesity induction. The cinnamon polyphenol extract treatment caused $23.3 \%$ and $25.4 \%$ reduction in serum and liver MDA concentration and elevation in serum TAC, liver SOD, CAT, and GSHPx of $91.2,62.6 \%, 21.9 \%$, and $36.0 \%$ in the HFD-fed rats $(P<0.001)$, which was like the control group $(P$ $>0.05)$.

3.4. Effect of Cinnamon Extract on Protein Levels in HFDFed Rats. SREBP-1c, LXRs, ACLY, and FAS expression in the HFD-fed rats increased by $75.1 \%, 98.7 \%, 106.0 \%$, and $81.7 \%$ in liver (Figure 1), respectively $(P<0.0001$ for all). SREBP-1c,
LXRs, ACL, and FAS expression decreased by 18.1\%, 27.9\%, $22.7 \%$, and $15.8 \%$, respectively $(P<0.05$ for all), when the HFD rats were treated with cinnamon polyphenol extract. All remained lower as compared to the control rats $(P>0.05$ for both).

PPAR $\alpha$ and IRS expression in liver in the HFD group were $71.3 \%$ and $67.0 \%$ lower than those in the control group (Figure 2; $P<0.001$ for both). Despite the respective 1.72- and 1.73-fold increase in PPAR $\alpha$ (Figure 2(a)) and IRS (Figure 2(b)) expression with cinnamon polyphenol extract treatment $(P<0.001$ for both), PPAR $\alpha$ and IRS expression levels still remained lower compared to the control group $(P<0.001$ for both $)$.

Expression of NF- $\kappa$ B increased by $92.2 \%$ in the liver in the HFD rats (Figure $3(\mathrm{a}) ; P<0.001$ ). The cinnamon polyphenol extract treatment partially restored NF- $\kappa \mathrm{B}$ expression levels in liver (by $23.3 \% ; P<0.05$; Figure $3(\mathrm{a})$ ) as compared to the control group. The induction of obesity was associated with 68.7 and $63.0 \%$ reduction in expression of $\mathrm{Nrf} 2$ and $\mathrm{HO}-1$ in liver $(P<0.001$; Figures $3(\mathrm{~b})$ and $3(\mathrm{c}))$, respectively. The cinnamon polyphenol extract treatment partially elevated the expression of Nrf2 and HO-1 in the liver (by $111.7 \%$ and $72.1 \%$; $P<0.001$; Figures 3(b) and 3(c)).

\section{Discussion}

High-fat dietary intake leads to insulin resistance (IR) and altered glucose and lipid metabolism [28]. Cinnamon polyphenols can respond to IR and are therefore useful 
TABLE 4: Effects of cinnamon polyphenol extract on oxidative stress and antioxidant status rats fed with HFD for 12 weeks.

\begin{tabular}{lcccc}
\hline Item & & \multicolumn{2}{c}{ Groups } & \\
& Control & Cinnamon & HFD & HFD + cinnamon \\
\hline Serum MDA (nmol/mL) & $0.68 \pm 0.04^{\mathrm{C}}$ & $0.64 \pm 0.03^{\mathrm{C}}$ & $1.76 \pm 0.03^{\mathrm{A}}$ & $1.35 \pm 0.03^{\mathrm{B}}$ \\
Liver MDA (nmol/mg protein) & $1.97 \pm 0.06^{\mathrm{C}}$ & $1.90 \pm 0.13^{\mathrm{C}}$ & $3.58 \pm 0.09^{\mathrm{A}}$ & $2.67 \pm 0.04^{\mathrm{B}}$ \\
Serum TAC (nmol Trolox Equiv. per mg protein) & $1.76 \pm 0.06^{\mathrm{A}}$ & $1.88 \pm 0.12^{\mathrm{A}}$ & $0.57 \pm 0.07^{\mathrm{C}}$ & $1.09 \pm 0.10^{\mathrm{B}}$ \\
Liver SOD (U/mg protein) & $202.29 \pm 5.80^{\mathrm{A}}$ & $206.14 \pm 7.31^{\mathrm{A}}$ & $91.71 \pm 3.98^{\mathrm{C}}$ & $149.14 \pm 2.03^{\mathrm{B}}$ \\
Liver CAT (U/mg protein) & $349.86 \pm 11.97^{\mathrm{A}}$ & $353.85 \pm 14.06^{\mathrm{A}}$ & $229.57 \pm 4.30^{\mathrm{C}}$ & $279.82 \pm 9.62^{\mathrm{B}}$ \\
Liver GSHPx (U/mg protein) & $53.67 \pm 4.25^{\mathrm{A}}$ & $54.86 \pm 3.56^{\mathrm{A}}$ & $23.42 \pm 2.56^{\mathrm{C}}$ & $31.86 \pm 2.48^{\mathrm{B}}$ \\
\hline
\end{tabular}

HFD, high-fat diet; MDA, malondialdehyde; TAC, total antioxidant capacity; SOD, superoxide dismutase; CAT, catalase; GSHPx, glutathione peroxidase. Data are expressed as mean \pm SE of 7 rats from each group. A, B, and C: means in the same row with different superscripts are significant $(P<0.05)$.

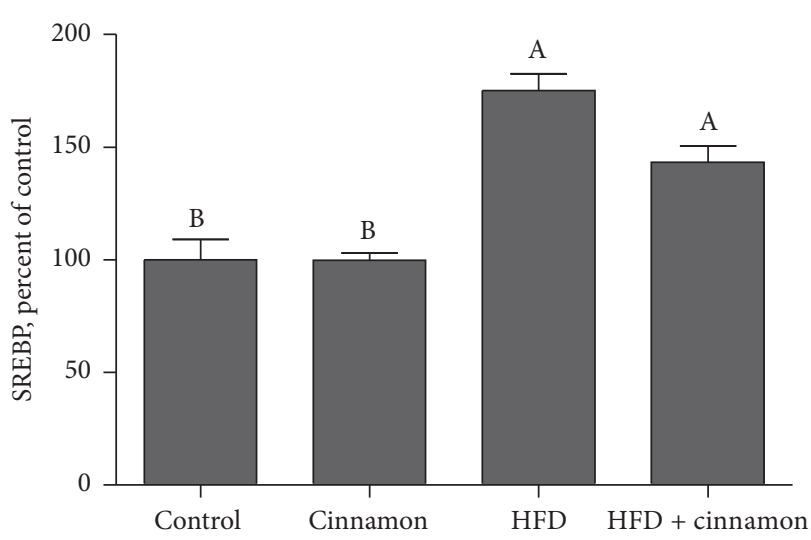

(a)

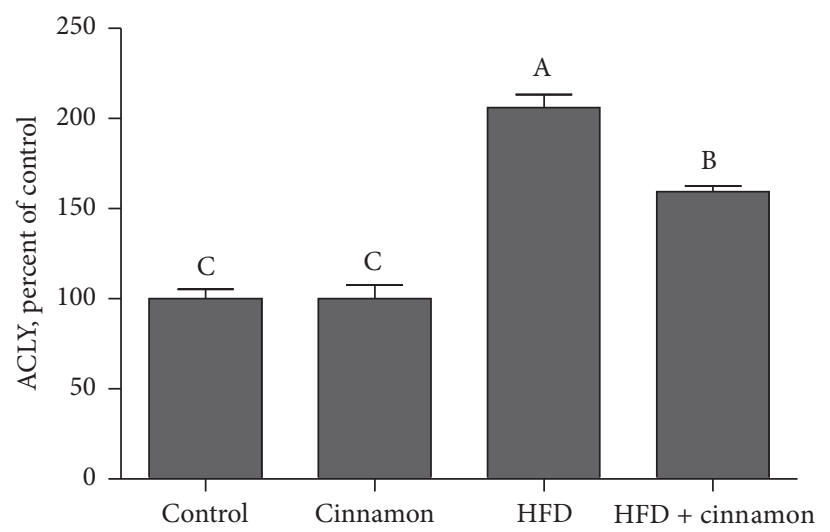

(c)

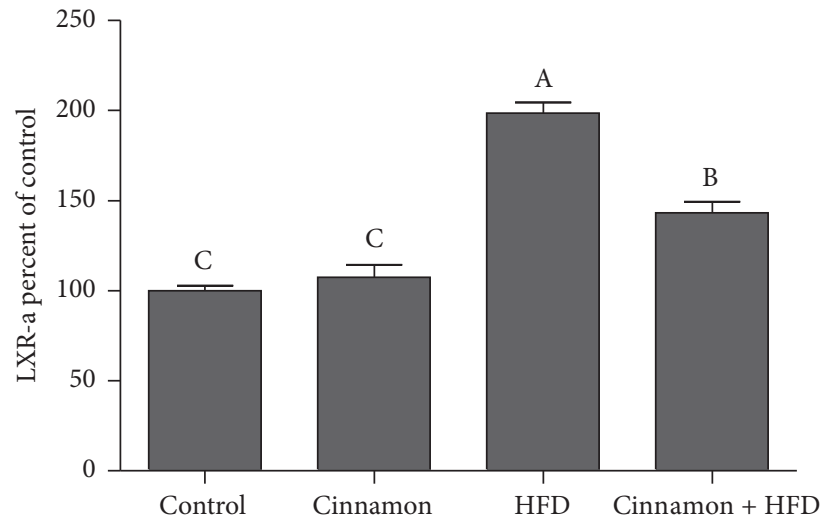

(b)

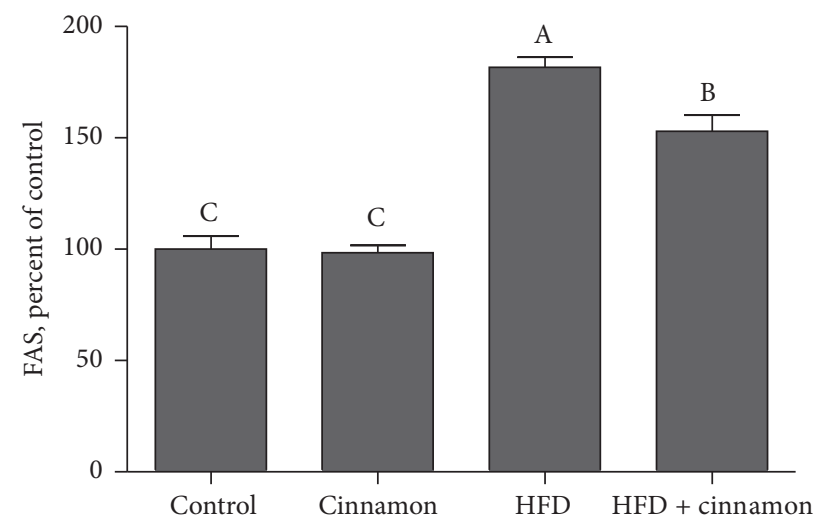

(d)

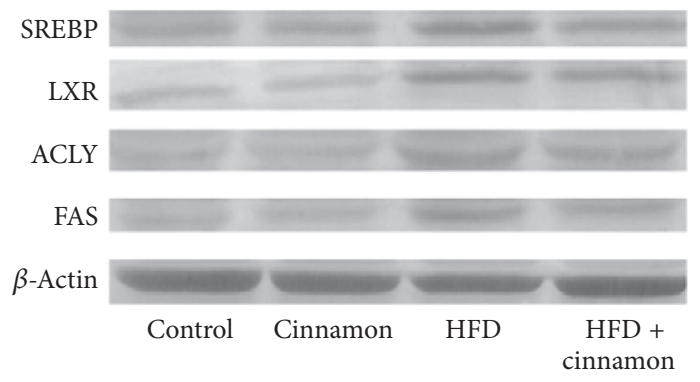

(e)

Figure 1: Hepatic SREBP-1c, LXRs, ACLY, and FAS expression levels in cinnamon polyphenol supplemented high-fat diet- (HFD-) fed rats and control groups. (a)-(d) show the expression level of SREBP-1c, LXRs, ACLY, and FAS in various groups. The intensity of the bands shown in (e) was quantified by densitometric analysis. Data are expressed as a ratio of normal control value (set to $100 \%$ ). Each bar represents the mean and standard error of mean. Blots were repeated at least 3 times $(n=3)$ and only a representative blot is shown in (e). $\beta$-Actin was included to ensure equal protein loading. 


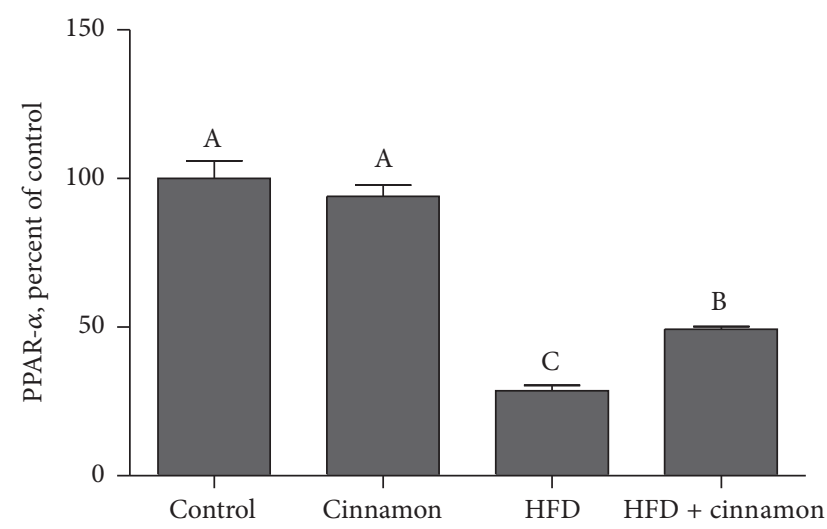

(a)

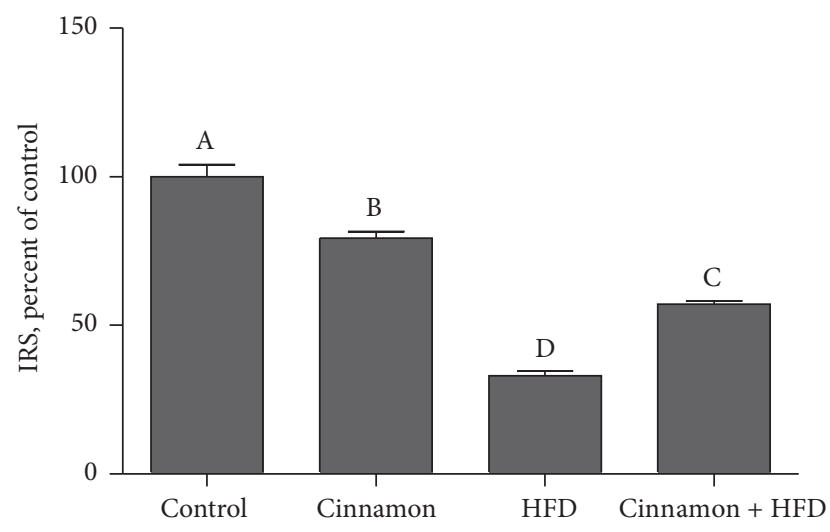

(b)

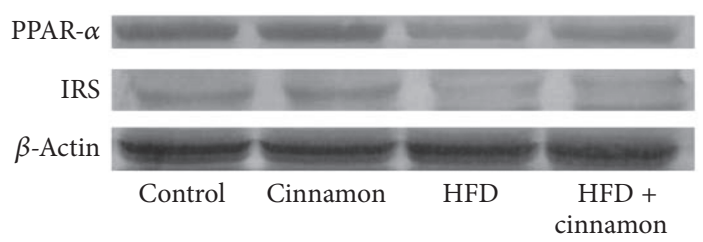

(c)

FIGURE 2: Hepatic PPAR $\alpha$ and IRS expression levels in cinnamon polyphenol supplemented high-fat diet- (HFD-) fed rats and control groups. (a) and (b) show the expression level of PPAR $\alpha$ and IRS in the groups. The intensity of the bands shown in (c) was quantified by densitometric analysis. Data are expressed as a ratio of normal control value (set to 100\%). Each bar represents the mean and standard error of mean. Blots were repeated at least 3 times $(n=3)$ and only a representative blot is shown in (c). $\beta$-Actin was included to ensure equal protein loading.

because of their insulin-enhancing and antioxidant properties [29]. Cinnamon extracts have been recognized as in vitro and in vivo insulin sensitizers $[22,30]$. The adverse effects of HFD/HFD on brain insulin signal changes were alleviated by the use of cinnamon, which suggests that cinnamon is associated with whole body insulin sensitivity and related changes, including hippocampal synaptic plasticity and cognition in the brain of neuroprotective effects [31,32]. Consistent with previous studies, our results demonstrated that cinnamon polyphenol extract supplementation improved body weight, visceral fat, and carbohydrate metabolism including glucose, insulin, and free fatty acid and lipid profiles (TC, TG, and HDL-C) and lipid peroxidation and antioxidant enzymes in the HFD-fed rats [19, 33-36]. Qin et al. [28] reported that cinnamon polyphenol extract increased the use of insulinregulated glucose in rats. In addition, Mang et al. [21] reported that cinnamon prevents IR by partially increasing insulin signaling pathway with high fructose diet.

Cinnamon extracts have also been shown to be useful in decreasing fasting plasma glucose, cholesterol, and triglycerides in diabetic patients [37]. Similarly, application of cinnamon extract reduced liver MDA levels in carbon tetrachloride-poisoned rats and improved SOD, CAT, and GSHPx activities [38]. Cinnamon has been shown to prevent hyperlipidemia and improved glucose tolerance in rats fed fructose/high fat $[22,39]$. However, a direct association between cinnamon polyphenol intake and regulated SREBP1c, LXRs, ACLY, and FAS expression by cinnamon polyphenol in the HFD-fed rats has yet to be established. Previous studies have shown that SREBP-1c has a regulatory role in the synthesis of lipogenic enzymes such as FAS, which inhibits TG accumulation in the liver, in fatty acid synthesis and lipid metabolism [8]. LXRs are also transcription factors that regulate fatty acid and cholesterol homeostasis and are expressed mainly in the liver and other tissues involved in lipid metabolism [40]. ACLY play a crucial role in obesityrelated complications in glucose and lipid homeostasis of mice liver [9]. An animal study has shown activation of LXR protection effects in obesity induced by high-fat diet [41]. In the present study, we demonstrated for the first time that cinnamon polyphenol intake significantly reduced the expression of hepatic SREBP-1c, LXRs, ACLY, and FAS. There are no earlier studies associated with examining the effects of cinnamon polyphenol treatment on the expression of SREBP1c, LXRs, ACL, and FAS in rats fed HFD to compare with this study. Nevertheless, it was reported that cinnamon prevented the hyperlipidemia in fructose-fed rats and improved glucose tolerance [39].

Peroxisome proliferator-activated receptors (PPARs), transcriptional factors complicated in the modulation of IR and adipogenesis, play key roles in regulating carbohydrate and lipid metabolism [42]. Activation of PPAR reduces serum triglycerides and raises serum HDL-cholesterol concentrations [43], whereas activation of PPAR $\gamma$ increases insulin sensitivity and causes antidiabetic effects [44]. IRS-1 plays an essential role in the pathway of insulin-stimulated signal transduction and binds the insulin receptor to its ultimate biological activities by a series of intermediates [45]. In a prior report, we showed that HFD in diabetic rats decreased PPAR $\gamma$ expression in the adipose tissue and reduced expression of 


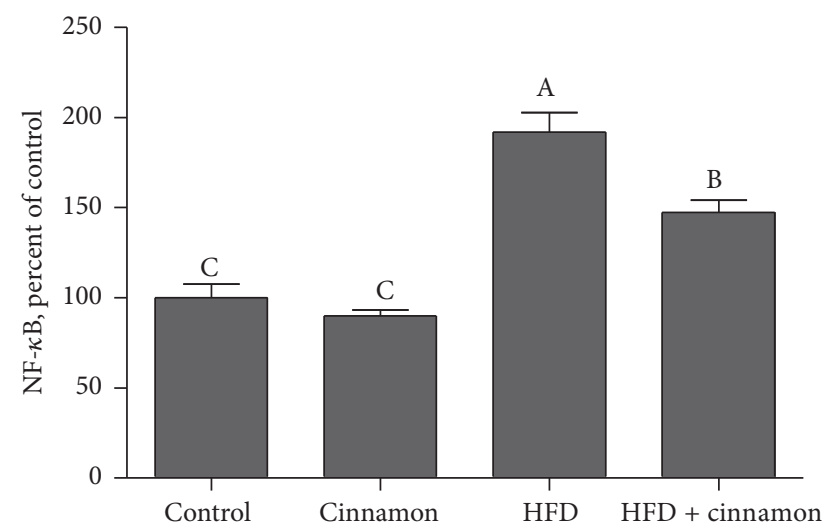

(a)

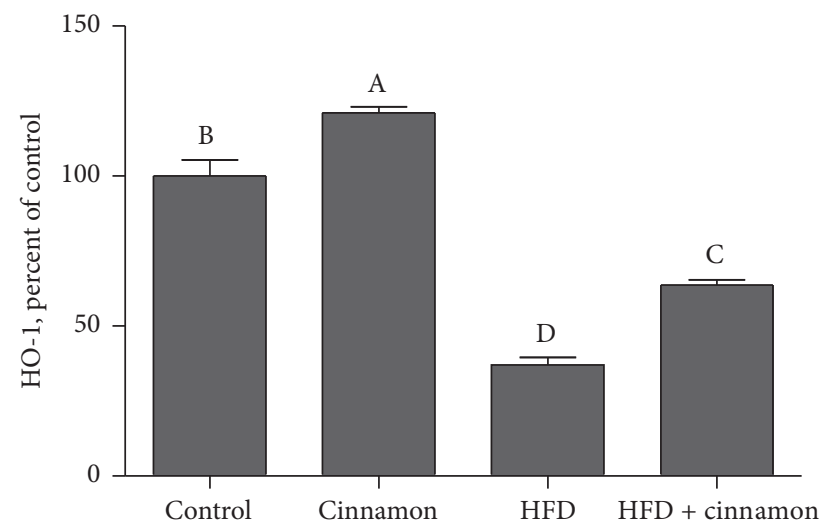

(c)

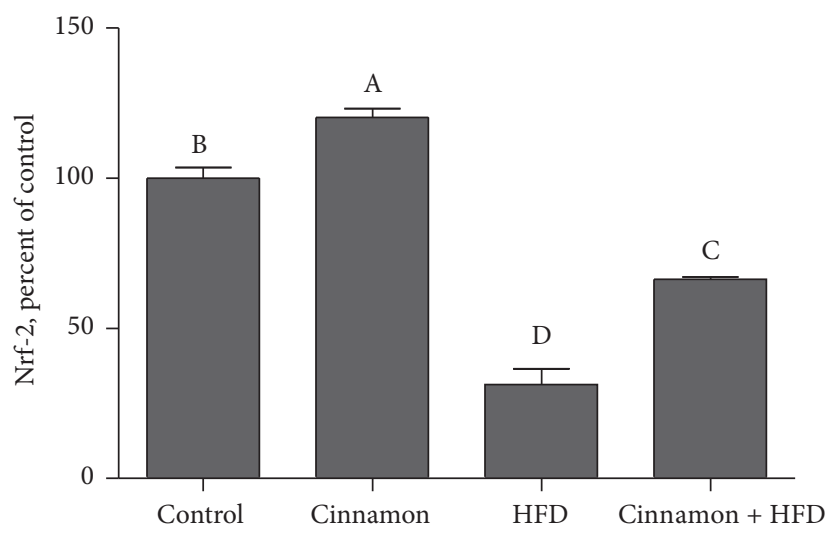

(b)

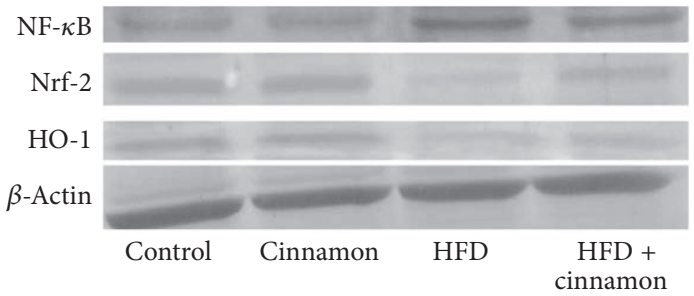

(d)

FIgURE 3: Hepatic NF- $\kappa$ B p65, Nrf2, and HO-1 expression levels in cinnamon polyphenol supplemented high-fat diet- (HFD-) fed rats and control groups. (a)-(c) show the expression level of NF- $\kappa \mathrm{B}$ p65, Nrf2, and HO-1 in the groups. The intensity of the bands shown in (d) was quantified by densitometric analysis. Data are expressed as a ratio of normal control value (set to 100\%). Each bar represents the mean and standard error of mean. Blots were repeated at least 3 times $(n=3)$ and only a representative blot is shown in (d). $\beta$-Actin was included to ensure equal protein loading.

IRS-1 in the liver and kidney [46]. In this study, cinnamon polyphenol increased PPAR $\alpha$ and IRS expression in the liver; this may have potential insulin sensitizing effect and may increase IR in a rat obesity model. In accordance with our findings, Sheng et al. [42] showed that the cinnamon extract could induce expression of PPAR $\gamma$ and PPAR $\alpha$ both in vitro and in vivo in mouse adipose cells. Similarly, Qin et al. [47] found that cinnamon extract supplementation resulted in reduced expression of interleukin-1 $\beta$ (IL-1 $\beta$ ), IL-6, and tumor necrosis factor- $\alpha$ (TNF- $\alpha$ ) mRNA while increasing expression of IR, IRS1, and IRS2 in hamster enterocytes.

$\mathrm{NF}-\kappa \mathrm{B}$ is a transcription factor that is responsible for controlling a DNA transcription and comprises cellular responses to various stimuli including free radicals. Kuhad and Chopra [48] reported that the signal transduction pathway for the activation of transcription factor NF- $\kappa \mathrm{B}$ was evoked by reactive oxygen species associated with hyperglycemia and by advanced glycosylated end products [48]. In the situation of oxidative stress and numerous cytokines, $\mathrm{NF}-\kappa \mathrm{B}$ is quickly released from $\mathrm{I} \kappa \mathrm{B}$ in order to stimulate the expression of chemotactic and matrix proteins of various cytokines involved in inflammation, immunological responses, and/or proliferation [49]. In the present study, cinnamon polyphenol reduced liver of NF- $\kappa \mathrm{B}$ expression in rats fed HFD (Figure 3). In a previous study, we have reported that HFD consumption enhances inflammation and NF- $\kappa$ B activation [50]. Fan et al. [51] showed that activity of NF- $\kappa \mathrm{B}$ increased in rats fed HFD. But there was no earlier study studying the effects of cinnamon polyphenol on the NF- $\kappa \mathrm{B}$ p 65 in the liver with which to compare this study. Nevertheless, in a previous study, it was shown that cinnamon-based treatment induced inhibition of NF- $\kappa \mathrm{B}$ and neuroinflammation and supported our present findings [52].

Another important mechanism contributing to cinnamon antiobesity is the upregulation of antioxidantdependent proteins. We found that expression of the proteins Nrf2 and HO-1 increased in HFD rats with cinnamon intake, indicating that this antioxidant mechanism may underlie reduced levels of lipid peroxidation in liver tissues. Nrf2 transcription factor is one of the most important antioxidant defense mechanisms that protect cells and tissues from various oxidative stresses [53]. Specifically, Nrf2 induces the expression of genes encoding antioxidant proteins, including HO-1, by binding to the antioxidant response element [54]. 
HO-1 is reported to be a highly effective therapeutic target for protection against oxidative stress and damage. HO-1 also is one of phase II detoxifying enzymes and exerts a strong antioxidant effect, and it is regulated by the redox-sensitive transcription factors. In addition, Nrf2 likely interferes with lipogenic and cholesterolemic pathways, inhibiting lipid accumulation and oxidative stress in the mouse liver after administration of HFD [55]. In the current study, cinnamon polyphenol d increased Nrf2 and HO-1 expression in liver of rats fed by HFD (Figure 3). Tuzcu et al. [50] showed similar reductions in $\mathrm{Nrf} 2$ and $\mathrm{HO}-1$ expressions as increased serum MDA in HFD-fed rats. In addition, cinnamaldehyde, an important flavor component in cinnamon essential oil upregulated $\mathrm{Nrf} 2$ expression, stimulated its translocation to the nucleus, and increased HO-1, NQO1, CAT, and GPx1 expression under high glucose conditions [7]. Wondrak et al. [56] reported that cinnamaldehyde and cinnamon extract upregulated cellular protein levels of Nrf2 in human colon cancer cells and recognized Nrf2 targets involved in the antioxidant response including HO-1 and gamma-glutamylcysteine synthetase.

\section{Conclusions}

In conclusion, cinnamon polyphenol has been reported to have several beneficial effects on obesity through the modulation of transcription factors including SREBP-1c, LXRs, NF- $\kappa \mathrm{B}$, and Nrf2 and several enzymes such as ACLY and FAS and insulin resistance, glucose, and lipid metabolism and antioxidant status. Cinnamon polyphenol may have a potential use in the management of hyperglycemia and hyperlipidemia.

\section{Disclosure}

Vijaya Juturu is employee of OmniActive Health Technologies Inc. (NJ, USA).

\section{Conflicts of Interest}

Authors have no competing conflicts of interest.

\section{Acknowledgments}

This study was sponsored by OmniActive Health Technologies Inc. (NJ, USA). This work was also supported in part by the Turkish Academy of Sciences.

\section{References}

[1] A. Shehzad, T. Ha, F. Subhan, and Y. S. Lee, "New mechanisms and the anti-inflammatory role of curcumin in obesity and obesity-related metabolic diseases," European Journal of Nutrition, vol. 50, no. 3, pp. 151-161, 2011.

[2] Y. Son, J.-S. Nam, M.-K. Jang, I.-A. Jung, S.-I. Cho, and M.H. Jung, "Antiobesity activity of Vigna nakashimae extract in high-fat diet-induced obesity," Bioscience, Biotechnology, and Biochemistry, vol. 77, no. 2, pp. 332-338, 2013.
[3] M.-L. Su, Y. He, Q.-S. Li, and B.-H. Zhu, "Efficacy of acetylshikonin in preventing obesity and hepatic steatosis in $\mathrm{db} / \mathrm{db}$ mice," Molecules, vol. 21, no. 8, article 976, 2016.

[4] W. Li, Y.-H. Shi, R.-L. Yang et al., "Effect of somatostatin analog on high-fat diet-induced metabolic syndrome: involvement of reactive oxygen species," Peptides, vol. 31, no. 4, pp. 625-629, 2010.

[5] C. T. Shearn, K. E. Mercer, D. J. Orlicky et al., "Short term feeding of a high fat diet exerts an additive effect on hepatocellular damage and steatosis in liver-specific PTEN knockout mice," PLOS ONE, vol. 9, no. 5, Article ID e96553, 2014.

[6] F. Wang, C. Pu, P. Zhou et al., "Cinnamaldehyde prevents endothelial dysfunction induced by high glucose by activating Nrf2," Cellular Physiology and Biochemistry, vol. 36, no. 1, pp. 315-324, 2015.

[7] Y. Wang, J. Viscarra, S.-J. Kim, and H. S. Sul, "Transcriptional regulation of hepatic lipogenesis," Nature Reviews Molecular Cell Biology, vol. 16, no. 11, pp. 678-689, 2015.

[8] S. Han, J. Jiao, W. Zhang et al., "Dietary fiber prevents obesityrelated liver lipotoxicity by modulating sterol-regulatory element binding protein pathway in C57BL/6J mice fed a highfat/cholesterol diet," Scientific Reports, vol. 5, Article ID 15256, 2015.

[9] Q. Wang, L. Jiang, J. Wang et al., "Abrogation of hepatic ATP-citrate lyase protects against fatty liver and ameliorates hyperglycemia in leptin receptor-deficient mice," Hepatology, vol. 49, no. 4, pp. 1166-1175, 2009.

[10] J. K. Reddy and T. Hashimoto, "Peroxisomal $\beta$-oxidation and peroxisome proliferator-activated receptor $\alpha$ : an adaptive metabolic system," Annual Review of Nutrition, vol. 21, pp. 193230, 2001.

[11] J. D. Horton, J. L. Goldstein, and M. S. Brown, "SREBPs: activators of the complete program of cholesterol and fatty acid synthesis in the liver," Journal of Clinical Investigation, vol. 109, no. 9, pp. 1125-1131, 2002.

[12] G. Boden, P. She, M. Mozzoli et al., "Free fatty acids produce insulin resistance and activate the proinflammatory nuclear factor- $\kappa$ B pathway in rat liver," Diabetes, vol. 54 , no. 12 , pp. $3458-$ $3465,2005$.

[13] C. Zhang, X. Lu, Y. Tan et al., "Diabetes-induced hepatic pathogenic damage, inflammation, oxidative stress, and insulin resistance was exacerbated in zinc deficient mouse model," PLoS ONE, vol. 7, no. 12, Article ID e49257, 2012.

[14] S. Elattar, S. Estaphan, E. A. Mohamed, A. Elzainy, and M. Naguib, "The protective effect of 1alpha, 25-dihydroxyvitamin $\mathrm{d} 3$ and metformin on liver in type 2 diabetic rats," The Journal of Steroid Biochemistry and Molecular Biology, 2016.

[15] G. Chinetti, J.-C. Fruchart, and B. Staels, "Peroxisome proliferator-activated receptors (PPARs): nuclear receptors at the crossroads between lipid metabolism and inflammation," Inflammation Research, vol. 49, no. 10, pp. 497-505, 2000.

[16] X. Ding, S. Fan, Y. Lu et al., "Citrus ichangensis peel extract exhibits anti-metabolic disorder effects by the inhibition of PPAR $\gamma$ and LXR signaling in high-fat diet-induced C57BL/6 mouse," Evidence-based Complementary and Alternative Medicine, vol. 2012, Article ID 678592, 10 pages, 2012.

[17] E. V. Fomenko and Y. Chi, "Mangiferin modulation of metabolism and metabolic syndrome," BioFactors, vol. 42, no. 5, pp. 492-503, 2016.

[18] V. Beejmohun, M. Peytavy-Izard, C. Mignon et al., "Acute effect of Ceylon cinnamon extract on postprandial glycemia: 
alpha-amylase inhibition, starch tolerance test in rats, and randomized crossover clinical trial in healthy volunteers," $B M C$ Complementary and Alternative Medicine, vol. 14, article 351, 2014.

[19] M. Shalaby and H. Saifan, "Some pharmacological effects of cinnamon and ginger herbs in obese diabetic rats," Journal of Intercultural Ethnopharmacology, vol. 3, no. 4, pp. 144-149, 2014.

[20] R. Hamidpour, M. Hamidpour, S. Hamidpour, and M. Shahlari, "Cinnamon from the selection of traditional applications to its novel effects on the inhibition of angiogenesis in cancer cells and prevention of Alzheimer's disease, and a series of functions such as antioxidant, anticholesterol, antidiabetes, antibacterial, antifungal, nematicidal, acaracidal, and repellent activities," Journal of Traditional and Complementary Medicine, vol. 5, no. 2, pp. 66-70, 2015.

[21] B. Mang, M. Wolters, B. Schmitt et al., "Effects of a cinnamon extract on plasma glucose, $\mathrm{HbAlc}$, and serum lipids in diabetes mellitus type 2," European Journal of Clinical Investigation, vol. 36, no. 5, pp. 340-344, 2006.

[22] K. Couturier, B. Qin, C. Batandier et al., "Cinnamon increases liver glycogen in an animal model of insulin resistance," Metabolism: Clinical and Experimental, vol. 60, no. 11, pp. 15901597, 2011.

[23] N. Boqué, J. Campión, R. de la Iglesia et al., "Screening of polyphenolic plant extracts for anti-obesity properties in Wistar rats," Journal of the Science of Food and Agriculture, vol. 93, no. 5, pp. 1226-1232, 2013.

[24] J. Malik, K. Munjal, and R. Deshmukh, "Attenuating effect of standardized lyophilized Cinnamomum zeylanicum bark extract against streptozotocin-induced experimental dementia of Alzheimer's type," Journal of Basic and Clinical Physiology and Pharmacology, vol. 26, no. 3, pp. 275-285, 2015.

[25] M. Karatepe, "Simultaneous determination of ascorbic acid and free malondialdehyde in human serum by HPLC-UV," LC-GC North America, vol. 22, no. 4, pp. 362-365, 2004.

[26] O. Erel, "A novel automated method to measure total antioxidant response against potent free radical reactions," Clinical Biochemistry, vol. 37, no. 2, pp. 112-119, 2004.

[27] K. Sahin, C. Orhan, M. Tuzcu et al., "Orally administered lycopene attenuates diethylnitrosamine-induced hepatocarcinogenesis in rats by modulating Nrf-2/HO-1 and Akt/mTOR pathways," Nutrition and Cancer, vol. 66, no. 4, pp. 590-598, 2014.

[28] B. Qin, H. Dawson, M. M. Polansky, and R. A. Anderson, "Cinnamon extract attenuates TNF- $\alpha$-induced intestinal lipoprotein ApoB48 overproduction by regulating inflammatory, insulin, and lipoprotein pathways in enterocytes," Hormone and Metabolic Research, vol. 41, no. 7, pp. 516-522, 2009.

[29] M. Hariri and R. Ghiasvand, "Cinnamon and Chronic Diseases," in Drug Discovery from Mother Nature, vol. 929 of Advances in Experimental Medicine and Biology, pp. 1-24, Springer International Publishing, Cham, 2016.

[30] R. A. Anderson, "Chromium and polyphenols from cinnamon improve insulin sensitivity," Proceedings of the Nutrition Society, vol. 67, no. 1, pp. 48-53, 2008.

[31] A. M. Stranahan, E. D. Norman, K. Lee et al., "Diet-induced insulin resistance impairs hippocampal synaptic plasticity and cognition in middle-aged rats," Hippocampus, vol. 18, no. 11, pp. 1085-1088, 2008.

[32] N. Marissal-Arvy, C. Batandier, J. Dallennes et al., "Effect of a high-fat-high-fructose diet, stress and cinnamon on central expression of genes related to immune system, hypothalamicpituitary-adrenocortical axis function and cerebral plasticity in rats," British Journal of Nutrition, vol. 111, no. 7, pp. 1190-1201, 2014.

[33] B. Qin, M. M. Polansky, and R. A. Anderson, "Cinnamon extract regulates plasma levels of adipose-derived factors and expression of multiple genes related to carbohydrate metabolism and lipogenesis in adipose tissue of fructose-fed rats," Hormone and Metabolic Research, vol. 42, no. 3, pp. 187-193, 2010.

[34] J. G. Wang, R. A. Anderson, G. M. Graham III et al., "The effect of cinnamon extract on insulin resistance parameters in polycystic ovary syndrome: a pilot study," Fertility and Sterility, vol. 88, no. 1, pp. 240-243, 2007.

[35] H. Cao, M. M. Polansky, and R. A. Anderson, "Cinnamon extract and polyphenols affect the expression of tristetraprolin, insulin receptor, and glucose transporter 4 in mouse 3T3-L1 adipocytes," Archives of Biochemistry and Biophysics, vol. 459, no. 2, pp. 214-222, 2007.

[36] A. Khaki, A. A. Khaki, L. Hajhosseini, F. S. Golzar, and N. Ainehchi, "The anti-oxidant effects of ginger and cinnamon on spermatogenesis dys-function of diabetes rats," African Journal of Traditional, Complementary and Alternative Medicines, vol. 11, no. 4, pp. 1-8, 2014.

[37] A. Khan, M. Safdar, M. M. Ali Khan, K. N. Khattak, and R. A. Anderson, "Cinnamon improves glucose and lipids of people with type 2 diabetes," Diabetes Care, vol. 26, no. 12, pp. 32153218, 2003.

[38] S. S. Moselhy and H. K. H. Ali, "Hepatoprotective effect of cinnamon extracts against carbon tetrachloride induced oxidative stress and liver injury in rats," Biological Research, vol. 42, no. 1, pp. 93-98, 2009.

[39] S. Kannappan, T. Jayaraman, P. Rajasekar, M. K. Ravichandran, and C. V. Anuradha, "Cinnamon bark extract improves glucose metabolism and lipid profile in the fructose-fed rat," Singapore Medical Journal, vol. 47, no. 10, pp. 858-863, 2006.

[40] Y. Lu, W. Xi, X. Ding et al., "Citrange fruit extracts alleviate obesity-associated metabolic disorder in high-fat diet-induced obese C57BL/6 mouse," International Journal of Molecular Sciences, vol. 14, no. 12, pp. 23736-23750, 2013.

[41] M. Gao and D. Liu, "The liver X receptor agonist T0901317 protects mice from high fat diet-induced obesity and insulin resistance," AAPS Journal, vol. 15, no. 1, pp. 258-266, 2013.

[42] X. Sheng, Y. Zhang, Z. Gong, C. Huang, and Y. Q. Zang, "Improved insulin resistance and lipid metabolism by cinnamon extract through activation of peroxisome proliferatoractivated receptors," PPAR Research, vol. 2008, Article ID 581348, 9 pages, 2008.

[43] G. Steiner, A. Hamsten, J. Hosking et al., "Effect of fenofibrate on progression of coronary-artery disease in type 2 diabetes: the Diabetes Atherosclerosis Intervention Study, a randomised study," The Lancet, vol. 357, no. 9260, pp. 905-910, 2001.

[44] J. M. Olefsky, "Treatment of insulin resistance with peroxisome proliferator-activated receptor $\gamma$ agonists," Journal of Clinical Investigation, vol. 106, no. 4, pp. 467-472, 2000.

[45] B. Cheatham and C. R. Kahn, "Insulin action and the insulin signaling network," Endocrine Reviews, vol. 16, no. 2, pp. 117142, 1995.

[46] K. Sahin, M. Tuzcu, C. Orhan et al., "Anti-diabetic activity of chromium picolinate and biotin in rats with type 2 diabetes induced by high-fat diet and streptozotocin," British Journal of Nutrition, vol. 110, no. 2, pp. 197-205, 2013. 
[47] B. Qin, M. M. Polansky, Y. Sato, K. Adeli, and R. A. Anderson, "Cinnamon extract inhibits the postprandial overproduction of apolipoprotein B48-containing lipoproteins in fructose-fed animals," Journal of Nutritional Biochemistry, vol. 20, no. 11, pp. 901-908, 2009.

[48] A. Kuhad and K. Chopra, "Tocotrienol attenuates oxidativenitrosative stress and inflammatory cascade in experimental model of diabetic neuropathy," Neuropharmacology, vol. 57, no. 4, pp. 456-462, 2009.

[49] S. K. Jain, J. L. Croad, T. Velusamy, J. L. Rains, and R. Bull, "Chromium dinicocysteinate supplementation can lower blood glucose, CRP, MCP-1, ICAM-1, creatinine, apparently mediated by elevated blood vitamin $\mathrm{C}$ and adiponectin and inhibition of $\mathrm{NF} \kappa \mathrm{B}, \mathrm{Akt}$, and Glut-2 in livers of zucker diabetic fatty rats," Molecular Nutrition \& Food Research, vol. 54, no. 9, pp. 13711380, 2010.

[50] M. Tuzcu, N. Sahin, C. Orhan et al., "Impact of chromium histidinate on high fat diet induced obesity in rats," Nutrition and Metabolism, vol. 8, article no. 28, 2011.

[51] J.-G. Fan, Y. Qian, X.-Y. Zheng, X.-B. Cai, and Y.-S. Lu, "Effects of pentoxifylline on hepatic nuclear factor-kappa B signaling pathway and insulin resistance in nonalcoholic steatohepatitis rats induced by fat-rich diet," Zhonghua Gan Zang Bing Za Zhi, vol. 14, no. 10, pp. 762-766, 2006.

[52] S.-C. Ho, K.-S. Chang, and P.-W. Chang, "Inhibition of neuroinflammation by cinnamon and its main components," Food Chemistry, vol. 138, no. 4, pp. 2275-2282, 2013.

[53] K. Sahin, C. Orhan, Z. Tuzcu, M. Tuzcu, and N. Sahin, "Curcumin ameloriates heat stress via inhibition of oxidative stress and modulation of Nrf2/HO-1 pathway in quail," Food and Chemical Toxicology, vol. 50, no. 11, pp. 4035-4041, 2012.

[54] J. W. Kaspar, S. K. Niture, and A. K. Jaiswal, "Nrf2:INrf2 (Keap1) signaling in oxidative stress," Free Radical Biology and Medicine, vol. 47, no. 9, pp. 1304-1309, 2009.

[55] Y. Tanaka, L. M. Aleksunes, R. L. Yeager et al., "NF-E2-related factor 2 inhibits lipid accumulation and oxidative stress in mice fed a high-fat diet," Journal of Pharmacology and Experimental Therapeutics, vol. 325, no. 2, pp. 655-664, 2008.

[56] G. T. Wondrak, N. F. Villeneuve, S. D. Lamore, A. S. Bause, T. Jiang, and D. D. Zhang, "The cinnamon-derived dietary factor cinnamic aldehyde activates the Nrf2-dependent antioxidant response in human epithelial colon cells," Molecules, vol. 15, no. 5, pp. 3338-3355, 2010. 


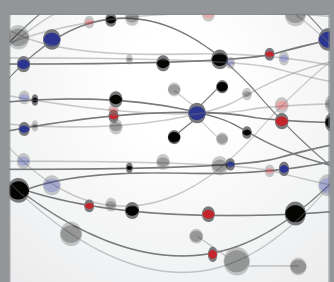

The Scientific World Journal
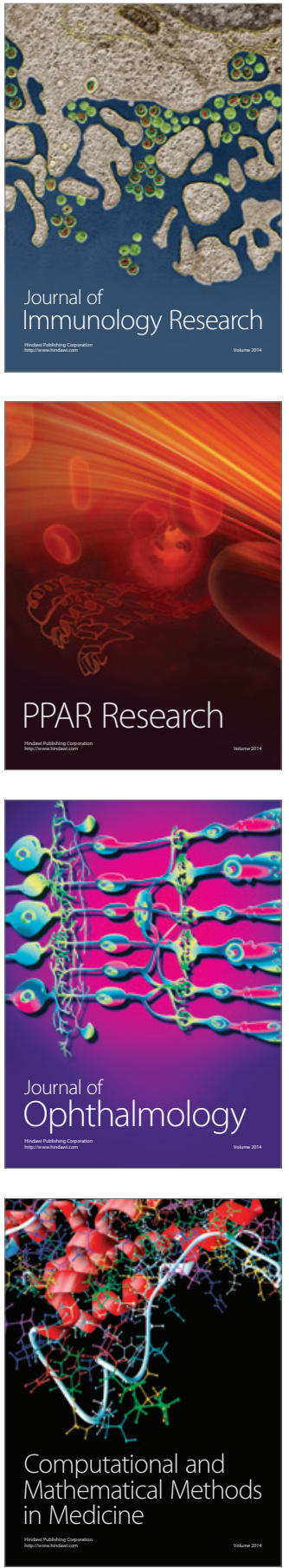

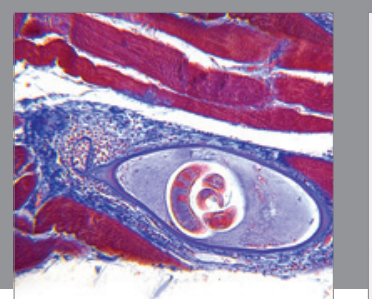

Gastroenterology Research and Practice
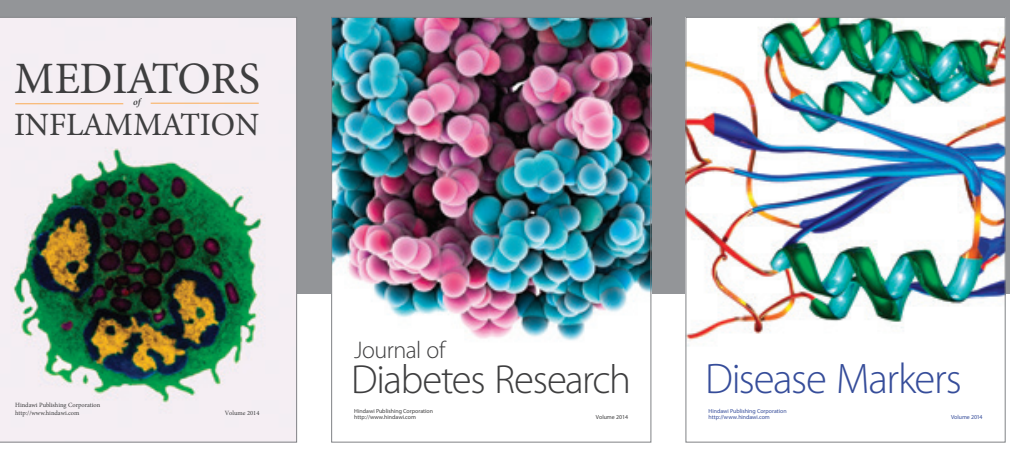

Disease Markers

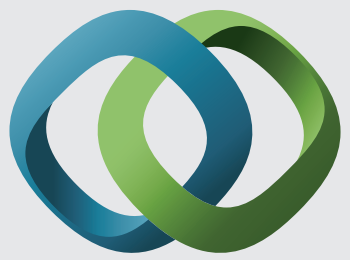

\section{Hindawi}

Submit your manuscripts at

https://www.hindawi.com
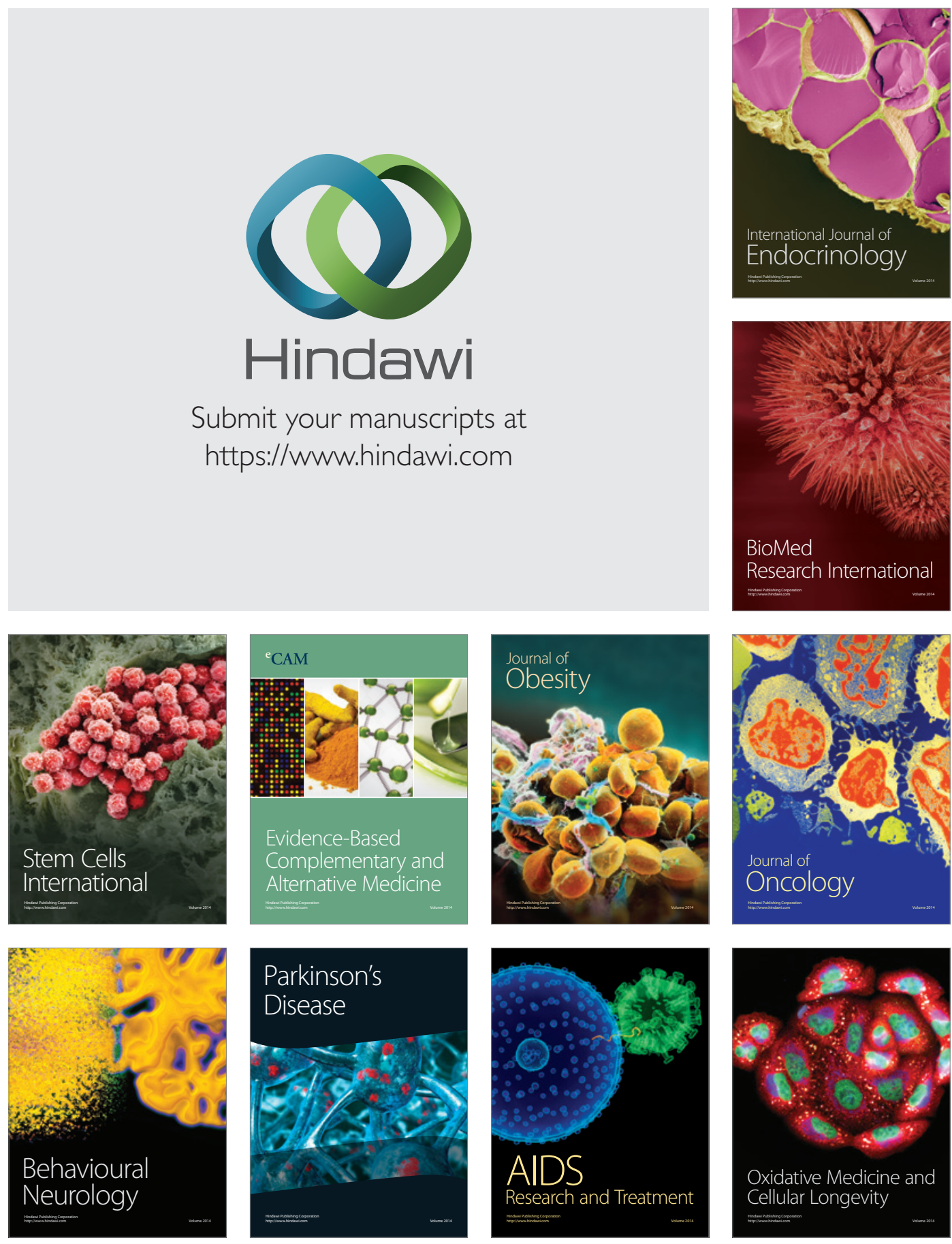